This journal is the official publication of Bangladesh Society of Physiologists (BSP)

Web URL: www.banglajol.info/index.php/JBSP

Abstracted /indexed in Index Copernicus, Director of Open Access Journal, HINARI Index Medicus for South East Asia Region, Google Scholar, 12OR, infobse index, Open J gate, Cite factor, Scientific indexing services

pISSN-1983-1213; e-ISSN-2219-7508

\title{
Article
}

Article information:

Received: 24th April 2021

Accepted: 20th Oct 2021

DOI: https://doi.org/10.3329/jbsp.v16i2.57566

Corresponding author:

Kawser Jahan, Associate Professor, Department of Physiology, Shahid Mansur Ali Medical College, Road\#10, Sector 11, Uttara, Dhaka 1230. Email: kawserjahan64@yahoo.com

Cite this article:

Jahan K, Begum N, Ferdousi S. Autonomic Neuropathy in Rheumatoid Arthritis: Relationship with seropositivity of Rheumatoid factor and disease activity. J Bngladesh Soc Physiol 2021;16(2): 70-76

This article is open access licensed under CC BY NC SA which allows readers copy, distribute, display, and perform the work and make derivative works based on it only for noncommercial purposes.

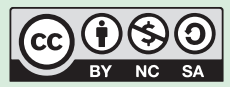

\section{Autonomic neuropathy in Rheumatoid Arthritis: Relationship with seropositivity of Rheumatoid factor and disease activity}

Kawser Jahan ${ }^{1}$, Noorzahan Begum² ${ }^{2}$, Sultana Ferdousi ${ }^{2}$

1. Department of Physiology, Shahid Mansur Ali Medical College,Dhaka

2. Department of Physiology,Bangabandhu Sheikh Mujib Medical University, Dhaka

\section{Abstract}

Background: Autonomic neuropathy (AN) has been recognized as a strong predictor of sudden cardiac death in Rheumatoid Arthritis (RA). Autonomic neuropathy may be assessed by five cardiovascular reflex tests. Objective: To find out the prevalence and severity of AN in RA and also to assess the correlation of inflammatory markers, disease severity and serological factor, Rheumatoid factor (RF) with autonomic reflex test parameters. Method: This cross sectional study was conducted on sixty (60) female RA patients, age range 18-50 years enrolled from the OutPatient Department of Rheumatology Wing, Department of Medicine, of Bangabandhu Sheikh Mujib Medical University (BSMMU). Age matched 30 apparently healthy females were control. Cardiac autonomic reactivity was assessed by five cardiovascular reflex tests as described by Ewing include heart rate response to standing, deep breathing, valsalva maneuver and blood pressure response to standing and sustained hand grip. Inflammatory activity in RA was assessed by serum rheumatoid factor (RF)level which was estimated by the latex agglutination test,C-reactive protein(CRP) and ESR and marker of disease activity was assessed by Disease activity score(DAS28 score) value. For statistical analysis, independent sample ' $t$ ' test chi-square test, pearson correlation coefficient test, spearman correlation test were used. Results: Among 60 RA patients, 43 (71.6\%) patients were RF positive. Frequency of AN 
in RA patients was significantly higher $(p<0.001)$ compared to control. AN was detected in $78 \%$ of RA patients. Among the RA patients $17.38 \%$ showed severe, $13.04 \%$ showed definite, $54.35 \%$ showed early involvement and $17.38 \%$ showed evidence of atypical pattern of AN. In addition, valsalva ratio and difference between maximum and minimum heart rate during deep breathing showed significant $(\mathrm{p}<0.05)$ negative correlation with autoantibody Rheumatoid factor(RF) whereas no significant correlation of autonomic nerve reactivity parameters with DAS28, CRP and ESR were found. Conclusion: Autonomic neuropathy was associated with RA. Autonomic neuropathy may be related to the presence of autoantibody RF in RA patients.

Key words: Rheumatoid Arthritis, Rheumatoid Factor, cardiovascular reflex test.

Introduction

$\mathbf{R}$ A is a common inflammatory connective tissue disease and its prevalence rate varies among different groups of people. Global prevalence of RA is $1 \%$ and it is same in Bangladesh. ${ }^{1} \mathrm{RA}$ is the $42^{\text {nd }}$ highest contributor to disability, ranking just below malaria. $^{2}$

Being an autoimmune disease RA affects primarily multiple joints, but also involves various organs including heart muscle, heart valves or the blood vessels of the heart. ${ }^{3}$ In most patients, presence of RF characterized by IgM has been detected in blood. ${ }^{4}$ Though cardiac involvement is silent, cardiovascular mortality is more than $40 \%$ in this group of patients. . $^{5-8}$

RA may alter autonomic nerve function and may produce sympatho-vagal imbalance. . $^{3,9-10}$ Though both peripheral and central nervous system involvement has been well recognized in RA but very few studies published report about the involvement of autonomic nervous system in RA. ${ }^{9,11-15 .}$

Tests of cardiovascular reûexes are sensitive, reproducible, simple, non-invasive and allow extensive evaluation of cardiovascular autonomic neuropathy (CAN). In 1992, Ewing et al. ${ }^{16}$ proposed 5 cardiovascular reflex tests to

Volume 16 No. 2 December 2021: 70-76 assess cardiac autonomic reflex activity. These include heart rate response to standing, deep breathing and valsalva maneuver and blood pressure response to standing and sustained hand grip. In our previous articles the results of Heart Rate Variability in RA and also autonomic reactivity in RA has been published. ${ }^{17,} 18-19$

Inflammation is one of the prime drivers of the cardiovascular disease in rheumatoid arthritis. ${ }^{12}$ Though few studies investigated autonomic function in RA but the relationship between inflammatory markers (CRP, ESR), disease severity (DAS-28) and autoantibody RF and cardiovascular autonomic reactivity were scarcely studied. ${ }^{6,10,11}$ Hence, the aim of this study was to evaluate the prevalence of autonomic neuropathy in RA and to explore the relationship between the inflammatory markers [CRP,ESR, disease severity score(DAS-28)\&auto-antibody $\mathrm{RF}$ ] and autonomic reflex action to determine the role of these risk factors on cardiovascular autonomic neuropathy in RA patients.

\section{Methods}

Setting \& study participants

Sixty diagnosed female RA patients with 18 to 50 years of age participated in this cross sectional study carried out by the department of Physiology, BSMMU during 2010. They were 
diagnosed according to American College of Rheumatology (ACR) classification. Among them, 43(71.6\%) patients were RF positive. Thirty age and BMI matched apparently healthy females were taken as control.

\section{Exclusion criteria}

RA patients with history of hypertension, heart disease, diabetes mellitus, renal diseases and psychic disorders were excluded from the study. Random blood sugar level and serum creatinine level were measured to exclude diabetes mellitus and renal failure.

\section{Procedure}

Before recruitment, the aim and objectives of the study were briefed to all the subjects and a written informed consent was taken from each subject .The protocol of this study was approved by the ethical review committee of BSMMU.

Resting pulse rate and supine resting blood pressure of all the subjects were also recorded. The status of the cardiovascular reflex responses were assessed by Ewing's five non-invasive cardiovascular reflex tests. To assess parasympathetic reactivity, $\mathrm{HR}$ response to valsalva, deep breathing, lying to standing was measured by valsalva ratio, difference between maximum and minimum $\mathrm{HR}$ during deep breathing and $30^{\text {th }}: 15^{\text {th }}$ ratio respectively. In addition, BP response to active standing and sustained handgrip was measured by fall of SBP and rise of DBP respectively to assess sympathetic reflex activity. Moreover, grading of CAN was done according to the description by Ewing et al. ${ }^{16}$ Disease Activity Score at 28 joints (DAS28) and Clinical Disease Activity Index criteria were used to assess their current disease activity. ${ }^{20-22}$

\section{Statistical analysis}

Data expressed as mean \pm SD \& frequent percent. Data was analyzed by Independent sample t test, chi-square test, Spearman's correlation and Pearson's correlation coefficient tests by using SPSS -26.

\section{Results}

Basal characteristics of the subjects were presented in table I. The mean resting pulse rate $(\mathrm{p}<0.05)$ and DBP $(\mathrm{p}<0.01)$ were significantly higher but mean SBP was not significantly different $(\mathrm{p}>0.05)$ in RA patients compared to control. Patients' clinical characteristics were shown in Table II. Frequency of autonomic neuropathy at different grade was shown in table III. Grading was done based on outcome of 5 cardiovascular reflex test. ${ }^{16}$ Among 90 patients, $78.3 \%$ of RA patients showed evidence of $\mathrm{AN}$ but none with AN was found in control group $(0 \%)$. No significant correlation of autonomic nerve function test parameters with DAS-28,CRP and ESR were found. Data were not presented. Figure 1 and 2 showed significant $(p<0.05)$ negative correlation of valsalva ratio and difference between maximum and minimum heart rate during deep breathing with RF in RA patients.

Table I : Socio demographic Data of both group $(\mathrm{N}=90)$

\begin{tabular}{lccc}
\hline Variables & Control $(\mathrm{n}=30)$ & RA patients $(\mathrm{n}=60)$ & $\mathrm{p}$ values \\
\hline Age $($ years $)$ & $36.50 \pm 11.50$ & $37.09 \pm 11.10$ & 0.803 \\
BMI $\left(\mathrm{Kg} / \mathrm{m}^{2}\right)$ & $23.88 \pm 2.27$ & $23.94 \pm 1.68$ & 0.876 \\
Pulse $($ beat $/ \mathrm{min})$ & $80.29 \pm 10.62$ & $85.34 \pm 11.22$ & $0.03^{*}$ \\
SBP $(\mathrm{mm}$ of $\mathrm{Hg})$ & $114.37 \pm 11.79$ & $116.19 \pm 11.30$ & 0.451 \\
DBP $(\mathrm{mm}$ of $\mathrm{Hg})$ & $68.70 \pm 7.59$ & $73.77 \pm 7.01$ & $0.001^{* * *}$ \\
\hline
\end{tabular}

Data were expressed as mean \pm SD. Statistical analysis was done by Independent sample t-test. $\mathrm{BMI}=$ Body Mass index, $\mathrm{SBP}=$ Systolic blood pressure, $\mathrm{DBP}=$ Diastolic blood pressure. ${ }^{*} * *=\mathrm{p}<0.01,{ }^{*}=\mathrm{p}<0.05$, $\mathrm{n}=$ number of subjects. 
Table II: RA Patients' clinical characteristics ( $\mathrm{N}=90)$

\begin{tabular}{lc}
\hline Clinical parameters & Values \\
\hline RF no. (\%) & $43(71.67 \%)$ \\
CRP mg/l, median (min-max) & $48(4-130)$ \\
VAS-GH,median( min-max) & $80(10-100)$ \\
ESR (mm/h) median(min-max) & $50(12-130)$ \\
Number of tender joints, median(min-max) & $20(1-28)$ \\
Number of swollen joints, median(min-max) & $0(0-18)$ \\
Deformity, median (min-max) & $2.5(0-8)$ \\
DAS-28, mean \pm SD(min-max) & $6.75 \pm 1.80(3.49-8.17)$ \\
\hline
\end{tabular}

RF-rheumatoid factor; min-minimum; max-maximum; VAS-visual analogue scale; GH- global health; ESRerythrocyte sedimentation rate; CRP- C-reactive protein; DAS28- Disease Activity Score based on 28 joint count

Table III: Grading of autonomic neuropathy in RA patients ( $\mathrm{N}=90)$

\begin{tabular}{lcc}
\hline Grading of Autonomic neuropathy & Control $(\mathrm{n}=30)$ & RA patients $(\mathrm{n}=60)$ \\
\hline Early involvement & $0(0 \%)$ & $25(54.35 \%)^{*}$ \\
Definite involvement & $0(0 \%)$ & $6(13.04 \%)^{* *}$ \\
Severe involvement & $0(0 \%)$ & $8(17.39 \%)$ \\
Atypical pattern & $0(0 \%)$ & $8(17.39 \%)$ \\
\hline Total & $0(0 \%)$ & $47(78.33 \%)$ \\
\hline
\end{tabular}

Data was expressed as percentage. Statistically analysed by chi square test. ${ }^{*} \mathrm{P}<0.05, \quad{ }^{*} \mathrm{P}<0.01$

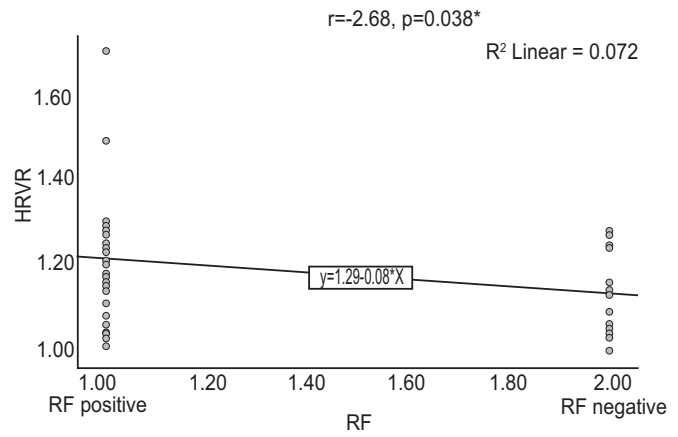

Figure 1: Correlation of valsalva ratio with rheumatoid factor. Statistical analysis was done by Spearman's correlation coefficient (r) test. HRVR: Heart rate response to valsalva maneuver (valsalva ratio), ${ }^{*}=\mathrm{p}<0.05$. Valsalva ratio is negatively correlated to rheumatoid factor

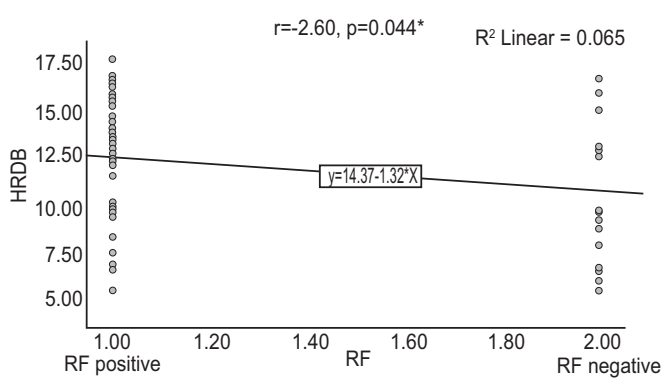

Figure 2: Correlation of $\Delta \mathrm{HR}$ during deep breathing with rheumatoid factor. Statistical analysis was done by Spearman's correlation coefficient (r) test. HRDB= Heart Rate Response to Deep Breathing, ${ }^{*}=p<0.05$. Difference between maximum and minimum $H R$ during deep breathing is correlated to serum rheumatoid factor. 


\section{Discussion}

In this study, five noninvasive cardiovascular reflex tests were used to detect autonomic neuropathy in RA patients and healthy control at various grade. Our results showed that 47 out of 60 RA patients had evidence of development of autonomic neuropathy at different grade and also high prevalence of AN was observed in RA patients and the healthy volunteers did not have autonomic neuropathy. These results in RA patients agrees well to the previous studies. ${ }^{23}$ Similar trends for AN in RA patients was noted by Saraswathi et al. ${ }^{24}$ However, Maule et al. ${ }^{12}$ found autonomic neuropathy in $15 \%$, Louthrenoo et al. ${ }^{9}$ in $47 \%$ and Toussirot et al. ${ }^{25}$ in $60 \%$ of RA patients and these frequency rates were much lower than that our study.

In contrast, Bekkelund et al. ${ }^{26}$ found no cardiovascular Autonomic Nervous System (ANS) dysfunction in RA patients whereas Geenen et al. ${ }^{27}$ found diminished ANS function in RA patients who had the disease for less than 1 year which was related to severity of pain and might had been related to the pathophysiological mechanism in RA.

These variations in different studies may be due to the difference in the way in which controls were selected and the criteria used to determine ANS dysfunction. Here, we considered single abnormal test as evidence of AN while Toussirot et al. ${ }^{25}$, considered AN present if a minimum of two tests were abnormal.

Little is known about exact mechanisms for autonomic neuropathy in RA patients. According to literature review, vasculitis, amyloid deposition and autoantibodies to ANS structures may be considered as risk factors for this autonomic neuropathy in patients of the present series. ${ }^{12-13}$ Results from the present study shows significant negative correlation between autonomic nerve function parameters and RF which suggests that severity of RA was correlated to autonomic nerve dysfunction and thus presence of autoantibody titer has an important role for autonomic neuropathy in RA. A tendency of greater cardiac autonomic nerve dysfunction with positive rheumatoid factor status and higher $\mathrm{C}$ reactive protein (CRP) levels has also been reported by some researchers. ${ }^{13,28-}$ 29 On the other hand we didn't find any significant correlation of autonomic nerve dysfunction with ESR, CRP and disease severity (DAS-28) in RA patients. This is in agreement with some previous studies. ${ }^{9,14,24}$ Though a number of studies have reported significant correlation between AN and disease factors, especially disease severity ${ }^{30-31}$ in RA.

\section{Conclusion}

From this study, it may be concluded that prevalence of autonomic neuropathy is very high in RA and autonomic neuropathy may be related to the presence of autoantibody (RF) in RA patients.

\section{Conflict of interest - None}

\section{References}

1. Statistics By Country For Rheumatoid Arthritis. [Internet] March 2005[Cited 2011] Available From: http://www.cureresearch.com/r/ rheumatoid_ arthritis/stats-country_printer.htm

2. Cross M, Smith E, Hoy D, Carmona L, Wolfe F, Vos T, et al. The global burden [6] of rheumatoid arthritis: estimates from the global burden of disease 2010 study. Ann Rheum Dis 2014; 73:1316-22.

3. Evrengül H, Dursunoglu D, Cobankara V, Polat B, Seleci D, Kabukeu S, Kaftan A, Semiz E, Kilic M. Heart rate variability in patients with rheumatoid arthritis. Rheumatol Int 2004; 24:198-202.

4. David AW. Timothy MC, John DF and Edward JB.Rheumatoid Arthritis. In: Oxford Textbook of Medicine. $4^{\text {th }}$ ed. 2005; Vol 2: 27-28.

5. Gerli R and Goodson NJ. Cardiovascular involvement in rheumatoid arthritis. Lupus 2005; $1: 679$.

6. Voskuyl AE. The heart and cardiovascular manifestations in rheumatoid arthritis. Rheumatology [Internet] [Cited 2010 May] 2006;15(4): iv4-iv7. DOI: 10.1093/rheumatology/ke1313

Volume 16 No. 2 December 2021: 70-76 
7. AcarG, Sayarlioðlu M, Akçay A, Sökmen A, Sökmen G, Yalçintap S , Nacar AB, Gündüz M, Tuncer C. Evaluation of atrial electromechanical delay and left atrial mechanical functions in patients with rheumatoid arthritis. Türk Kardiyol DernAr ${ }^{\circ} .2009$; $37: 4-10$.

8. Kitas GD and Erb N. Tackling ischemic heart disease in rheumatoid arthritis. Rheumatology. 2003; 42: 607-13.

9. Louthrenoo W, Ruttanaumpawan P, Aramrattana A and Sukitawut W. Cardiovascular autonomic nervous system dysfunction in patients with rheumatoid arthritis and systemic lupus erythematosus. Q J Med1999; 92:97-102.

10. Kamal A. Assessment of autonomic function in patients with rheumatoid arthritis using spectral analysis 7 approximate entropy method. Neurosciences 2007; 12(2): 136-39

11. Bennett PH and Scott JT. Autonomic neuropathy in rheumatoid arthritis. Ann Rheum Dis 1965; 24: 161-68. Doi:10.1136/ard.24.2.161

12. Maule S, Quadri R, Mirante D, Pellerito A, Marucco E, Marnone C, Vergani D, Chiandussi L \&Zanone M. Autonomic nervous systemdysfunction in systemic lupus erythematosus and rheumatoid arthritis: possible pathogenic role of auto antibodies to autonomic nervous structures. Clin Exp Immunol 1997; 110:423-27.

13. Sandhu V and Allen SC. The effects of age, seropositivity and disease duration on autonomic cardiovascular reflexes in patients with rheumatoid arthritis. Int J Clin Pract 2004; 58(8):740-45.

14. Aydemir M, Yazisiz V, Basarici I, Avci AB, Erbasan F, Belgi A, Terzioglu E. Cardiac autonomic profile in rheumatoid arthritis and systemic lupus erythematosus. Lupus 2010; 19:255-65.

15. Bidikar MP and Ichaporia RB.Autonomic (sympathetic) nervous system involvement in rheumatoid arthritis patients. Indian J Physiol Pharmacol 2010; 54(1):73-79.

16. Ewing DJ. Analysis of heart rate variability and other non-invasive tests with special reference to diabetes mellitus. In: Banister R And Mathias CG (eds).Autonomic failure a text book of clinical disorders of the autonomic nervous system. New York: Oxford University Press; 1992.p. 312-33.

17. Jahan K, Begum N \&Ferdousi S. Power spectral analysis of heart rate variability in female rheumatoid arthritis patients. J Bangladesh Soc Physiol 2012; 7(1):8-12.

18. Jahan K, Begum N \&Ferdousi S. Parasympathetic nerve function status in female with rheumatoid arthritis. J Bangladesh Soc Physiol 2013; 8(1):2125.

19. Ferdousi S, Jahan K \& Begum N. Relationship of sympathetic dysfunction with disease duration in female rheumatoid arthritis patients. J Bangladesh Soc Physiol 2015; 10(1):17-20.

20. Prevoo ML, van't Hof MA, Kuper HH et al. Modiûed disease activity scores that include twentyeight-joint counts. Development and validation in a prospective longitudinal study of patients with rheumatoid arthritis. Arthritis Rheum1995; 38(1): $44-48$

21. Hensor EM, Emery P, Bingham SJ et al. Discrepancies in categorizing rheumatoid arthritis patients by DAS 28(ESR) and DAS-28(CRP):Can they be reduced? Rheumatology (Oxford) $2010 ; 49,1521-29$.

22. Fleischmann R, van der Heijde D, Koenig AS et al. How much does Disease Activity Score in 28 joints ESR and CRP calculations underestimate disease activity compared with the Simpliued Disease ActivityI ndex? Ann Rheum Dis 2015;74:113237

23. Aggarwal D, Singla S. Prevalence of autonomic neuropathy in patients of rheumatoid arthritis and its correlation with disease severity. J Clin of Diagn Res 2017; 11(4): OC09-OC13 DOI:10.7860/ JCDR/2017/24182.9614

24. Saraswathi PV, Neelambikai N, Mahesh A, Govindarajan K. Cardiovascular [14] parasympathetic nervous system dysfunction in female rheumatoid arthritis patients. Indian J Physiol Pharmacol 2013;57:23-30.

25. Toussirot E, Serratrice G, Valentin P. Autonomic nervous system involvement in rheumatoid arthritis.50 Cases. J Rheumatol1993; 20(9):150814.

26. Bekkelund SI, Mellgren SI, Proven A and Husby G. Quantified neurological examination with emphasis on motor and sensory functions in patients with rheumatoid arthritis and controls. Br J Rheumatol 1996; 35(11):1116-21.

27. Geenen R, Godaert GL, Jacobs JW, Peters ML, Bijlsma JW. Diminished autonomic nervous system 
responsiveness in rheumatoid arthritis of recent onset.J Rheum 1966; 23: 258-64.

28. Klein CM, Vernino S, Lennon VA, Sandroni P, Fealey RD, Benrud-Larson L, et al. The spectrum of autoimmune autonomic neuropathies. Ann Neurol 2003;53(6):752-58.

29. Lazzerini PE, Acampa M, Capecchi PL, Hammoud M, Maffei S, Bisogno S, et al. Association between high sensitivity $\mathrm{C}$-reactive protein, heart rate variability and corrected QT interval in patients with chronic inflammatory arthritis. Eur J Intern Med 2013;24(4):368-74.

30. Anichkov DA, Shostak NA, Ivanov DS. Heart rate variability is related to disease activity and smoking in rheumatoid arthritis patients. Int $\mathrm{J}$ Clin Pract 2007;61(5):777-83.

31. Yadav RK, Gupta R, Deepak KK. A pilot study on short term heart rate variability and its correlation with disease activity in Indian patients with rheumatoid arthritis. Indian J Med Res 2012; 136(4):593-98. 